\title{
Is advice for breakfast consumption justified? Results from a short-term dietary and metabolic experiment in young healthy men
}

\author{
Ambroise Martin ${ }^{1,2}$, Sylvie Normand ${ }^{1}$, Monique Sothier ${ }^{1}$, Jocelyne Peyrat ${ }^{1}$, Corinne Louche-Pelissier ${ }^{1}$ \\ and Martine Laville ${ }^{1 *}$ \\ ${ }^{1}$ Human Nutrition Research Centre, Batiment 1, Edouard Herriot Hospital, Lyon, France \\ ${ }^{2}$ INSERM U189, BP12, 69921 OULLINS Cedex, France
}

(Received 22 April 1999 - Revised 3 December 1999 - Accepted 10 January 2000)

\begin{abstract}
Short-term (2 weeks) effects of the consumption of a high-energy $(2920 \mathrm{~kJ}(700 \mathrm{kcal}))$ or lowenergy $(418 \mathrm{~kJ}(100 \mathrm{kcal}))$ breakfast on dietary patterns, blood variables and energy expenditure (indirect calorimetry) were compared in ten free-living healthy young men in a crossover study. During the high-energy breakfast, total energy intake was increased, the intake of protein and lipids was unchanged but the intake of carbohydrates was increased. Thus, 48 (SD 4) \% of energy came from carbohydrates in the high-energy breakfast compared with 42 (SD 5) \% in the lowenergy breakfast. Excluding breakfast, the macronutrient composition of the diet remained identical in the two situations. After the high-energy breakfast, fasting serum triacylglycerol concentration was higher and HDL-cholesterol concentration was lower than after the lowenergy breakfast. A high glycaemic response was observed in the morning after the high-energy breakfast period, while there was a peak of free fatty acids after the low-energy breakfast. The high-energy breakfast induced a strong inhibition of fat oxidation throughout the day. Although long-term adaptation to a high-energy breakfast cannot be excluded, the high-energy breakfast in this study did not appear to be favourable to health. Our results do not support the current advice to consume more energy at breakfast.
\end{abstract}

Breakfast: Energy: Carbohydrate oxidation: Fat oxidation: Dietary recommendations

The usefulness of breakfast consumption is well recognised by nutritionists. The omission of breakfast or consumption of a low-energy breakfast relates to dietary patterns which are unfavourable for health (Morgan et al. 1986a). Insufficiency of micronutrient consumption which is not compensated for at other meals, a higher proportion of fat in the total diet and increased values of serum cholesterol in both children (Resnicow, 1991) and adults (Stanton \& Keast, 1989) or trouble in cognition (Benton \& Parker, 1998) have been observed. Many dietary surveys in developed countries indicate that the spontaneous average consumption of energy at breakfast in breakfast eaters is between 15 and $20 \%$ of total daily energy intake (Hercberg et al. 1996 (France); Wrinkler et al. 1999 (Germany)). While the current recommendation in most developed countries is to increase the energy content of breakfast, little data support this recommendation. Moreover, nutritional surveys in the School Breakfast Program subjects raise questions about the pertinence of increasing breakfast energy content (Devaney et al. 1995).

Thus, the purpose of the present study was to give greater insight into the influence of the energy content of breakfast on dietary and metabolic patterns. Short-term (2 weeks) effects of the consumption of a high-energy $(2920 \mathrm{~kJ}$ $(700 \mathrm{kcal}))$ or low-energy $(418 \mathrm{~kJ}(100 \mathrm{kcal}))$ breakfast on dietary patterns, blood variables and energy expenditure (indirect calorimetry) were compared in ten free-living healthy young men in a crossover study.

\section{Subjects and methods}

Subjects

Ten healthy men (age 28 (SD 2) years, weight 69.7 (SD $3.0) \mathrm{kg}$, height 177 (SD 2) cm, BMI 22.2 (SD 0.5) kg/m²) were recruited for the study. Each gave informed consent for the protocol which was approved by the Ethical Committee Lyon A, according to Huriet Law. During the two 2-week experimental periods, subjects ate their breakfast at the Human Nutrition Research Centre between 07.00 and 09.00 hours under supervision. They were asked to eat the whole breakfast without any leftover; time for consumption was free and ranged between 15 and $30 \mathrm{~min}$. After the breakfast, the subjects went to work, with the only

* Corresponding author: Professor Martine Laville, fax +33 47211 7865, email martine.laville@chu-lyon.fr 
Table 1. Composition of breakfasts

\begin{tabular}{lccc}
\hline & Protein $(\mathrm{g})$ & Fat $(\mathrm{g})$ & Carbohydrate $(\mathrm{g})$ \\
\hline Low-energy breakfast & & & \\
Tea or coffee & - & - & - \\
Sugar $(10 \mathrm{~g})$ & - & - & 10 \\
Rusk $(10 \mathrm{~g})$ & 1 & - & 7 \\
Butter $(5 \mathrm{~g})$ & - & $4 \cdot 2$ & - \\
Total $(\mathrm{g})$ & 1 & $4 \cdot 2$ & 17 \\
Energy $(\mathrm{kJ})$ & $16 \cdot 7$ & 158 & $284 \cdot 2$ \\
Energy $(\%)$ & $3 \cdot 6$ & $34 \cdot 4$ & 62 \\
High-energy breakfast & - & - & - \\
Tea or coffee & - & - & 10 \\
Sugar $(10 \mathrm{~g})$ & $8 \cdot 4$ & 1 & 58 \\
Bread $(100 \mathrm{~g})$ & - & $16 \cdot 8$ & - \\
Butter $(20 \mathrm{~g})$ & - & - & $20 \cdot 7$ \\
Jam $(30 \mathrm{~g})$ & 5.5 & 1.5 & 11.6 \\
Yoghurt $(125 \mathrm{~g})$ and sugar $(5 \mathrm{~g})$ & 1 & - & 18 \\
Fruit $(150 \mathrm{~g})$ & 14.9 & 19.3 & 118.3 \\
Total $(\mathrm{g})$ & 249 & 726 & 1978 \\
Energy $(\mathrm{kJ})$ & 8.4 & $24 \cdot 6$ & 67 \\
Energy $(\%)$ & & & \\
\hline
\end{tabular}

obligation being to record any food ingested during the day. At the end of each experimental period, subjects participated in the metabolic test at the centre. Subjects were advised to maintain their usual moderate physical activity during the study.

\section{Study design}

The main variable of the study was the energy content of the breakfast, as a low-energy, moderate-fat breakfast $(418 \mathrm{~kJ}$ (100 kcal), 34.4\% energy from fat) or a high-energy, low-fat breakfast $(2920 \mathrm{~kJ}$ (700 kcal), $24.6 \%$ energy from fat) (Table 1). Breakfast composition was of the continental type and representative of the traditional French breakfast, as indicated by nutritional surveys. The energy level was randomly assigned so that five subjects ate the low-energy breakfast and five the high-energy breakfast during the first 2-week period; this was the same for the second 2-week period. These two experimental periods were separated by 4 weeks of ad libitum feeding (Fig. 1(a)). During the two 2-week experimental periods and the last 2 weeks of the free-eating period, the subjects recorded all food intake

(a)

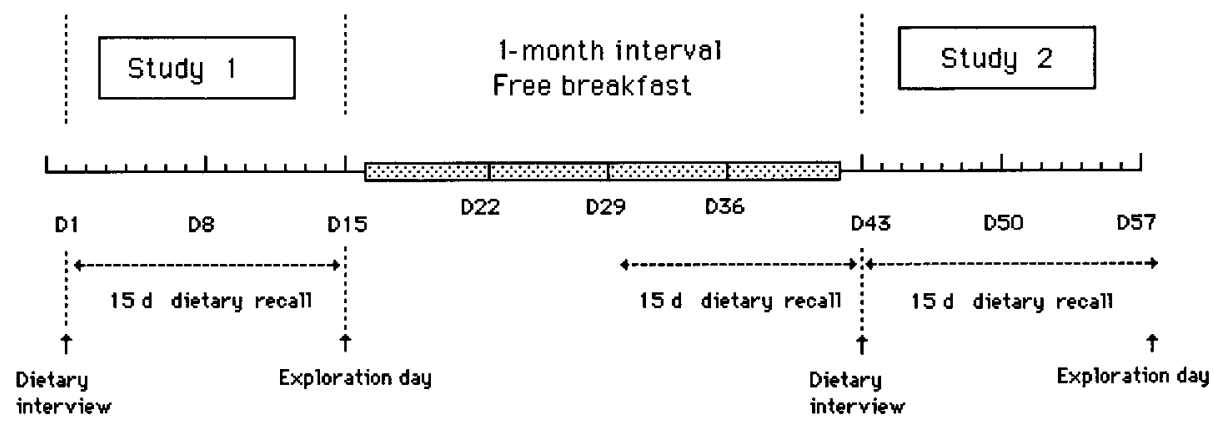

(b)

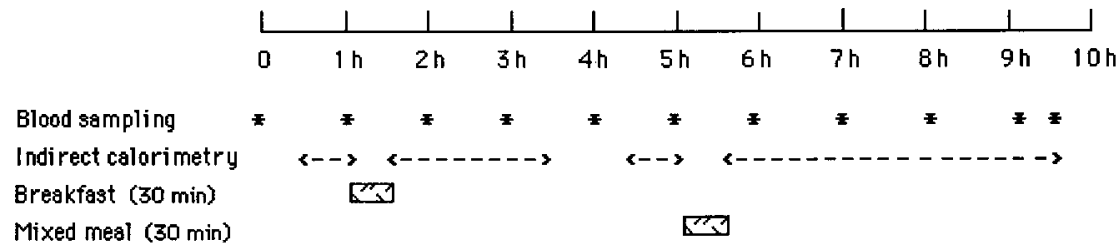

Fig. 1. Study design: (a), general study design (dietary intervention and food record); (b), exploration day (design of the metabolic test at the end of each dietary intervention period). During the study periods the subjects received either a low- or high-energy breakfast in a crossover design or a freely-selected breakfast. For details of breakfasts see Table 1. 
using an appropriate booklet. Ingested quantities were estimated using the photograph book validated for the French study Suvimax (Le Moullec et al. 1996). A dietitian controlled all dietary records. At regular intervals during the day, the subjects recorded their hunger sensation on a visual analog scale (De Castro \& Elmore, 1988).

\section{Metabolic test}

The metabolic test was performed on the 15 th day of each period: the subjects arrived at the Centre at 07.00 hours after an overnight fast; a catheter was placed in the forearm vein. At 08.00 hours they consumed the breakfast corresponding to the experimental period within $30 \mathrm{~min}$, whereafter they remained at rest throughout the day until 17.00 hours. Every hour (Fig. 1(b)) blood samples were withdrawn and indirect calorimetry was performed, using a ventilatedhood indirect calorimeter (Deltatrac; Datex, Finland). At 12.00 hours, they consumed the same standardised wellbalanced mixed meal within $30 \mathrm{~min}$, which provided $15.3 \%$ energy from protein, $30.8 \%$ from fat and $53.9 \%$ from carbohydrate. Each hour, the following serum variables were determined using automated enzymatic methods: glucose, triacylglycerol, free fatty acids, total cholesterol, HDL-cholesterol after phosphotungstate precipitation. LDL-cholesterol was calculated using Friedewald formula (Friedewald et al. 1972). Insulin was determined by radioimmunoassay and urine $\mathrm{N}$ by chemiluminescence.

\section{Calculations}

Nutrient intakes were estimated from the dietary records by computation using the Regal program (GENI, Micro 6, Nancy, France) and the French food tables (Favier et al. 1995). Calculations of substrate oxidation from indirect calorimetry data were made using published equations (Ferranini, 1988). The area under the lipid oxidation curve was calculated from 270 to 510 min (after the standardised lunch). Values are expressed as mean values and standard deviations for the ten subjects for the whole 2-week period. Comparisons between the periods were made by non-parametric paired statistical test of Mann-Whitney.

\section{Results}

\section{Anthropometric data}

Anthropometric data compared between the two experimental periods were similar for the ten subjects: mean body weights at the end of the experimental periods were 69.7 (SD 3.0) kg after the low-energy breakfast and 69.3 (SD $2.9) \mathrm{kg}$ after the high-energy breakfast. Weight variations during the low- and high-energy breakfast periods were $-0.5(\mathrm{SD} 0.1) \mathrm{kg}$ and $-0.4(\mathrm{SD} 0.1) \mathrm{kg}$ respectively, corresponding to a BMI $22 \cdot 2$ (SD 0.5) and $22 \cdot 1$ (SD 0.6) $\mathrm{kg} / \mathrm{m}^{2}$ respectively.

\section{Dietary patterns}

Total energy intake and breakdown within the day. Average daily energy intakes were similar during the 2-week experimental periods (Fig. 2); thus intakes were averaged for each experimental condition for the whole period. As shown in Table 2, total energy intake was significantly higher during the high-energy breakfast period than during the two other periods. However, while breakfast provided $2502 \mathrm{~kJ}$ more during this period than during the other experimental period, the excess in energy supply for the whole day was only $1483 \mathrm{~kJ}$. The contribution of the breakfast to total energy intake was less than $10 \%$ for the low-energy breakfast and more than $25 \%$ for the high-energy breakfast. In contrast with the subjects receiving the high-energy breakfast or subjects in the free-diet period, subjects on the low-energy breakfast significantly increased their energy intake during the other meals $(P=0 \cdot 0051)$. However, this compensation was spread out all over the eating occasions so that, when expressed in $\mathrm{kJ}$, there were no significative

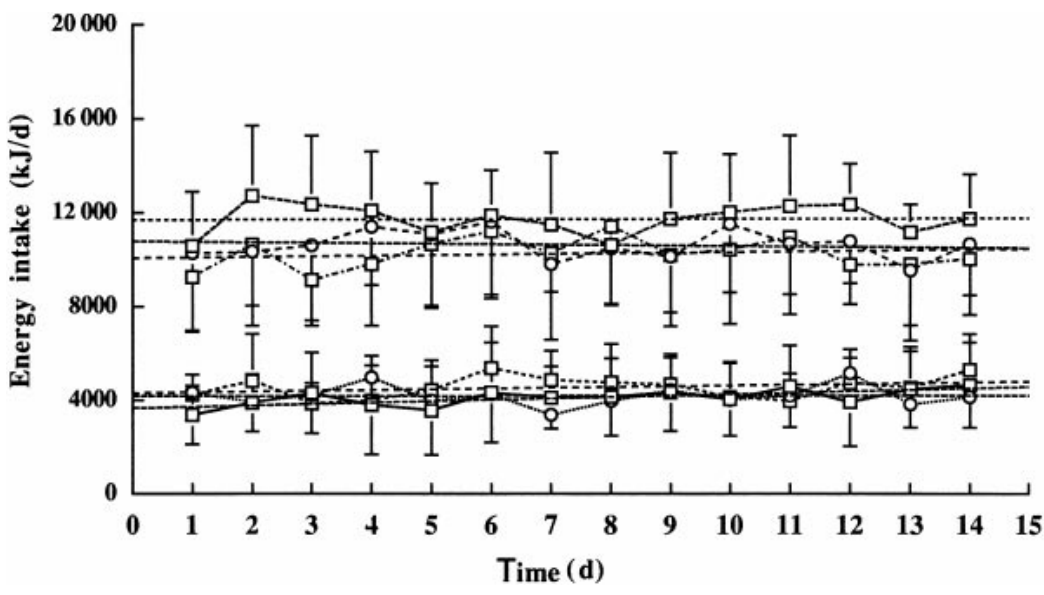

Fig. 2. Energy intake at lunch (lower lines) and for the whole day (upper lines) during the two 2-week experimental periods. Straight lines represent the calculated linear regression for the period. Values are means for ten subjects with standard deviations represented by vertical bars. During the experimental periods the subjects received either a low- or a high-energy breakfast in a crossover design or a freely-selected breakfast. For details of breakfasts see Table 1. 
Table 2. Daily patterns of energy intake of subjects consuming a low- or high-energy breakfast in a crossover design or a freely-selected diet for a 2-week period*

(Mean values and standard deviations for ten subjects)

\begin{tabular}{|c|c|c|c|c|c|c|}
\hline & \multicolumn{2}{|c|}{$\begin{array}{l}\text { Low-energy } \\
\text { breakfast }\end{array}$} & \multicolumn{2}{|c|}{ Free diet } & \multicolumn{2}{|c|}{$\begin{array}{l}\text { High-energy } \\
\text { breakfast }\end{array}$} \\
\hline & Mean & SD & Mean & SD & Mean & SD \\
\hline Total daily energy intake $(\mathrm{kJ})$ & $10254^{a}$ & 1789 & $10604^{b}$ & 1889 & $11737^{b}$ & 1141 \\
\hline Energy intake excluding breakfast (kJ) & $9790^{\mathrm{a}}$ & 1793 & $8682^{b}$ & 1923 & $8778^{b}$ & 1140 \\
\hline \multicolumn{7}{|l|}{ Energy from breakfast } \\
\hline $\mathrm{kJ}$ & $464^{a}$ & 8 & $1923^{b}$ & 598 & $2964^{b}$ & 8 \\
\hline$\%$ of total energy & 5 & 1 & 19 & 6 & 27 & 3 \\
\hline \multicolumn{7}{|l|}{ Energy from morning snack } \\
\hline kJ & $577^{a}$ & 497 & $96^{\mathrm{b}}$ & 84 & $117^{\mathrm{b}}$ & 117 \\
\hline$\%$ of total energy & 6 & 5 & 1 & 1 & 1 & 1 \\
\hline \multicolumn{7}{|l|}{ Energy from lunch } \\
\hline $\mathrm{kJ}$ & 4548 & 694 & 4138 & 1258 & 4080 & 711 \\
\hline$\%$ of total energy & $46^{a}$ & 7 & 39 & 6 & $35^{\mathrm{b}}$ & 3 \\
\hline \multicolumn{7}{|l|}{ Energy from afternoon snack } \\
\hline $\mathrm{kJ}$ & 451 & 309 & 506 & 268 & 602 & 376 \\
\hline$\%$ of total energy & 4 & 2 & 4 & 2 & 5 & 3 \\
\hline \multicolumn{7}{|l|}{ Energy from dinner } \\
\hline $\mathrm{kJ}$ & 4055 & 1020 & 3846 & 773 & 3766 & 598 \\
\hline$\%$ of total energy & $38^{a}$ & 6 & 35 & 7 & $31^{\mathrm{b}}$ & 4 \\
\hline \multicolumn{7}{|l|}{ Energy from evening snack } \\
\hline $\mathrm{kJ}$ & 159 & 213 & 100 & 130 & 213 & 272 \\
\hline$\%$ of total energy & 1 & 2 & 1 & 1 & 1 & 2 \\
\hline
\end{tabular}

${ }^{*}$ For details of breakfasts see Table 1.

${ }^{a, b}$ Mean values within a row with unlike superscript letters were significantly different $(P<0.05)$.

differences in energy intake between the studies for each eating occasion except for the breakfast and the morning snack. However, when energy intake was expressed as percentage of daily intake, there were significant differences for the lunch and the dinner.

There was a significant difference in hunger rating (44 (SD 12) $\mathrm{mm}$ for the low-energy breakfast $v .23$ (SD 17) $\mathrm{mm}$ for the high-energy breakfast, $P<0.05$ ) only in the morning at 10.00 hours, while there was no difference in hunger sensation at 12.00 hours before lunch (58 (SD 13) v. 53 (SD 18) $\mathrm{mm}$ respectively, $P=0.074$ ).

Distribution of energy between nutrients. The results are shown in Table 3. The expression of the results as percentage for the whole day clearly indicated a better distribution of nutrients during the high-energy breakfast period: there was an increase in energy intake from carbohydrate and a decrease in energy intake from fat and protein. Expressed in absolute amounts, only energy intake from carbohydrate was significantly increased. The ingestion of fat and proteins was similar for the two experimental periods. In contrast, when the breakfast was omitted from the calculations, an inverse pattern was obtained: there was no difference in the proportion of nutrients expressed in percentages and significant differences appeared for the absolute levels of proteins and fat.

Since the order of the experimental periods was randomly

Table 3. Macronutrient intake (including and excluding breakfast) of subjects consuming a low- or high-energy breakfast in a crossover design or a freely-selected diet for a 2-week period*

(Mean values and standard deviations for ten subjects)

\begin{tabular}{|c|c|c|c|c|c|c|c|c|c|c|c|c|}
\hline & \multicolumn{6}{|c|}{ Including breakfast } & \multicolumn{6}{|c|}{ Excluding breakfast } \\
\hline & \multicolumn{2}{|c|}{$\begin{array}{l}\text { Low-energy } \\
\text { breakfast }\end{array}$} & \multicolumn{2}{|c|}{ Free-diet } & \multicolumn{2}{|c|}{$\begin{array}{l}\text { High-energy } \\
\text { breakfast }\end{array}$} & \multicolumn{2}{|c|}{$\begin{array}{c}\text { Low-energy } \\
\text { breakfast }\end{array}$} & \multicolumn{2}{|c|}{ Free-diet } & \multicolumn{2}{|c|}{$\begin{array}{c}\text { High-energy } \\
\text { breakfast }\end{array}$} \\
\hline & Mean & SD & Mean & SD & Mean & SD & Mean & SD & Mean & SD & Mean & SD \\
\hline \multicolumn{13}{|l|}{ Protein } \\
\hline $\mathrm{kJ}$ & $17^{\mathrm{a}}$ & 2 & 16 & 2 & $15^{b}$ & 2 & 18 & 2 & 17 & 2 & 17 & 2 \\
\hline$\%$ of energy & 1655 & 226 & 1580 & 217 & 1705 & 163 & $1639^{a}$ & 226 & $1421^{b}$ & 196 & $1455^{b}$ & 167 \\
\hline \multicolumn{13}{|l|}{ Fat } \\
\hline $\mathrm{kJ}$ & $40^{\mathrm{a}}$ & 5 & 40 & 5 & $37^{b}$ & 4 & 41 & 6 & 41 & 4 & 41 & 6 \\
\hline$\%$ of energy & 3979 & 786 & 4025 & 803 & 4163 & 614 & $3791^{\mathrm{a}}$ & 790 & 3444 & 769 & $3444^{\mathrm{b}}$ & 618 \\
\hline \multicolumn{13}{|l|}{ Carbohydrate } \\
\hline $\mathrm{kJ}$ & $42^{\mathrm{a}}$ & 5 & 45 & 6 & $48^{\mathrm{b}}$ & 4 & 41 & 6 & 42 & 5 & 42 & 6 \\
\hline$\%$ of energy & $4176^{a}$ & 1095 & $4569^{b}$ & 1225 & $5463^{\mathrm{b}}$ & 828 & 3904 & 1099 & 3574 & 1158 & 3494 & 832 \\
\hline
\end{tabular}

${ }^{*}$ For details of breakfasts see Table 1.

a,b Mean values within a row with unlike superscript letters were significantly different $(P<0.05)$ 
assigned, and records of free-diet period were made between the two experimental periods, it was verified that the previous experimental period did not induce dietary modifications during the free-diet period. Indeed, energy intakes at breakfast were not significantly different during the free-diet period: 1900 (SD 518) kJ for the five subjects who began with the low-energy breakfast and 1950 (SD 735 ) $\mathrm{kJ}$ for those who began with the high-energy breakfast period.

\section{Metabolic tests}

The results are shown in Figs 3 and 4. Basal values of serum variables were similar for glucose, insulin, total cholesterol and LDL-cholesterol. After the high-energy breakfast period, fasting triacylglycerol was significantly higher than basal values $(1.37$ (SD 0.26) v. 0.94 (SD 0.10) $\mathrm{mmol} / \mathrm{l}$ respectively, $P<0.05)$, whereas fasting free fatty acids (296 (SD 39) v. 345 (SD 45) $\mu \mathrm{mol} / 1$ respectively, $P<0.05$ ) and fasting HDL-cholesterol (1.21 (SD 0.07) $v . \quad 1.34$ (SD 0.07 ) $\mathrm{mmol} / 1$ respectively, $P<0.05$ ) were significantly lower than at the end of the low-energy breakfast period. The pattern of glycaemia differed between the two periods after the breakfast and before the lunch, but not after the standardised lunch (Fig. 3(a)). The pattern of blood insulin was similar to that of glucose (Fig. 3(b)). The concentration of free fatty acids (Fig. 3(c)) was higher after the low-energy breakfast and it was still different from those of the other group $1 \mathrm{~h}$ after the beginning of the standardised lunch. Serum triacylglycol concentrations (Fig. 3(d)) were significantly higher throughout the day (except $3 \mathrm{~h}$ after lunch) at the end of the high-energy breakfast period $(P<0.05)$. However, there was no clear enhancement of post-prandial lipaemia after the standardised lunch in the high-energy breakfast group, whereas the increase was significant $3 \mathrm{~h}$ after the breakfast. The values of HDL-cholesterol did not vary significantly throughout the day and always remained significantly lower after the high-energy breakfast than after
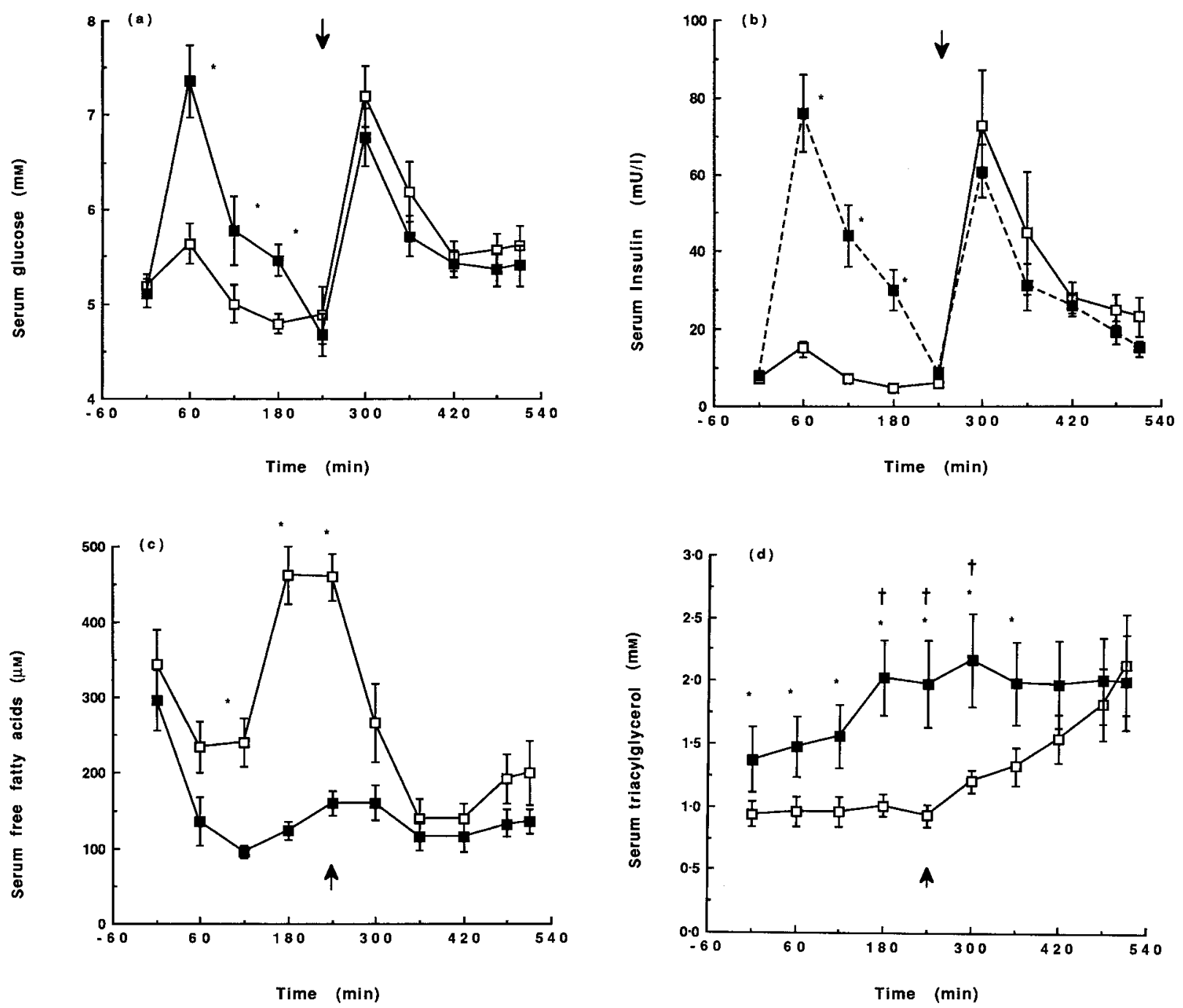

Fig. 3. Serum variables during the metabolic test: (a), glucose; (b), insulin; (c), free fatty acids; (d), triacylglycerol. $\square$, After the low-energy breakfast; $\mathbf{a}$, after the high-energy breakfast; $\downarrow$, lunch time $(240 \mathrm{~min})$. For details of breakfasts see Table 1 . Values are means for ten subjects with standard deviations represented by vertical bars. Mean values were significantly different from those after the high-energy breakfast: * $P<0.05$; Mean values were significantly different from those at time $0: \uparrow P<0.05$. 

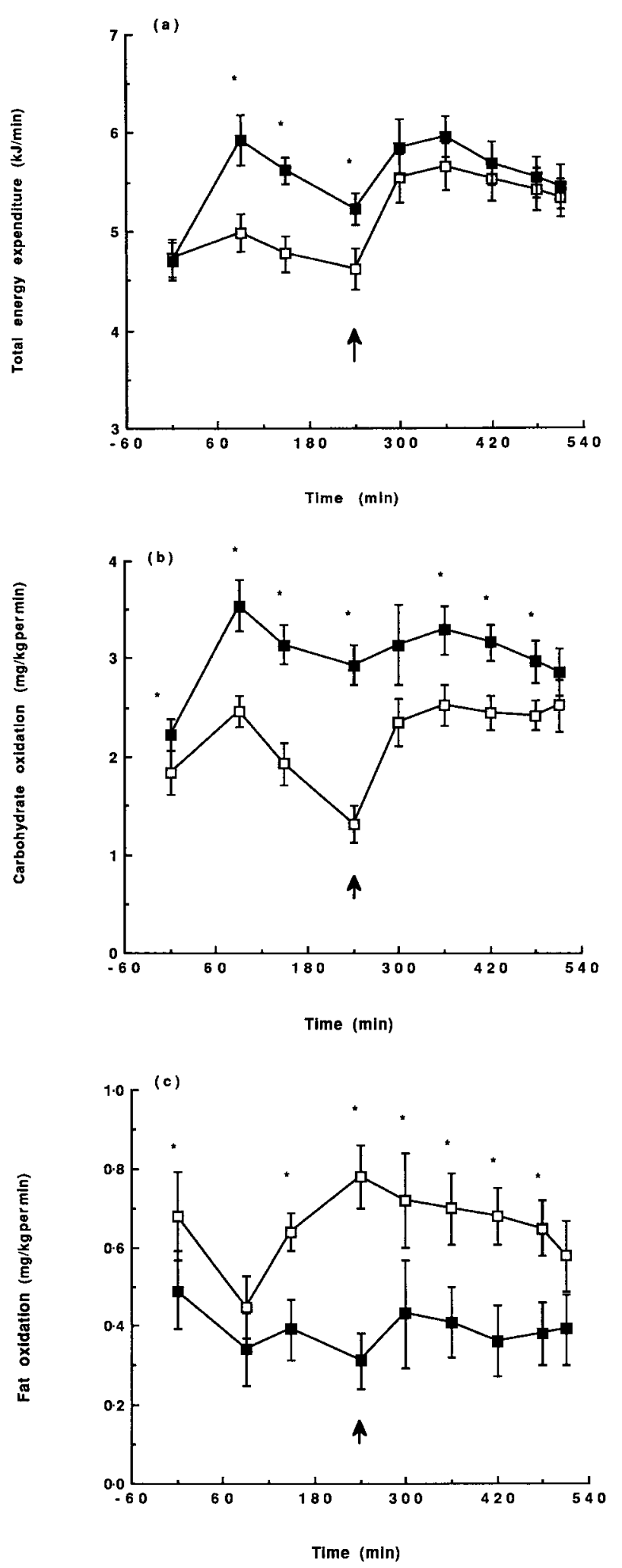

Fig. 4. Energy expenditure and substrate oxidation determined by indirect calorimetry: (a), total energy expenditure; (b), carbohydrate oxidation; (c), fat oxidation. $\square$, After the low-energy breakfast; $\mathbf{\square}$, after the high-energy breakfast; $\uparrow$, lunch time (240 min). For details of breakfasts see Table 1 . Values are means for ten subjects with standard deviations represented by vertical bars. Mean values were significantly different from those after the high-energy breakfast: ${ }^{*} P<0.05$. the low-energy breakfast (results not shown). The patterns of total cholesterol and LDL-cholesterol were similar throughout the day and identical at the end of the two periods (results not shown).

Total energy expenditure (Fig. 4(a)), determined by indirect calorimetry, was significantly higher only during the morning after the high-energy breakfast than after the low-energy breakfast $(P<0.05)$. However, there were differences in substrate oxidation: after the high-energy breakfast period, carbohydrate oxidation (Fig. 4(b)) remained high throughout all the tested periods, whereas lipid oxidation (Fig. 4(c)) was low, and did not change despite the ingestion of the standardised mixed lunch providing $30 \%$ of energy as fat. After the standardised lunch, lipid oxidation was 11.24 (SD 1.21) g and 6.13 (SD $1.67) \mathrm{g}$ after the ingestion of the low-energy and the highenergy breakfast respectively $(P<0 \cdot 05)$. Diet-induced thermogenesis, expressed as the percentage of the energy content of the meal, was not different in the morning during and after the two types of breakfast (4.29 (SD 1.37) \% for the low-energy and 4.88 (SD 0.36) \% for the high-energy breakfast) or during the lunch (4.26 (SD 0.39) \% for the low-energy breakfast and 5.18 (SD 0.59) \% for the highenergy breakfast).

\section{Discussion}

Similarly to many people in developed countries (Ruxton \& Kirk, 1997), $74 \%$ of French adults consume a breakfast with an energy content of less than $25 \%$ of total daily energy intake (Hercberg et al. 1996). Thus, if nutrition policies are to recommend an increase in energy consumption at breakfast, this should be supported by strong data. In order to test the influence of energy intake at breakfast on dietary and metabolic adaptation, we chose to compare two extreme values of typical continental breakfasts consumed in freeliving conditions; for this reason, no metabolic test was performed at the end of the free-diet period. Unpublished data from the Suvimax study, (S. Hertzberg, personal communication) indicates that a continental breakfast was consumed by $81 \%$ of French breakfast eaters, providing $1740 \mathrm{~kJ}$ (or $17.5 \%$ of total daily energy), with $12 \%$ of energy from protein, $25 \%$ from fat and $63 \%$ from carbohydrate. Since it is generally agreed that lipid consumption is too high in the French population, we chose a high-energy breakfast that provided the increase in energy from carbohydrates (up to $67 \%$ of breakfast energy). Daily spontaneous energy and nutrient intakes were of the same order of magnitude for the ten subjects of the study. Moreover, the energy content of the standardised lunch was similar to that spontaneously reported by the subjects.

As reported in some epidemiological surveys (Nicklas et al. 1993), the consumption of high-energy breakfasts led to a significantly higher energy consumption for the whole day. The nutrient breakdown for the whole day seems to be more favourable, tending to be close to the recommendations of nutritionists (30-35\% energy from fat), as was noted in many studies (Nicklas et al. 1993). However, when it is possible to perform calculations from published data, the absolute values of fat intake are frequently unchanged (for example, see Morgan et al. 1986b), indicating that the 
decrease in the percentage of energy from fat is due to the breakfast composition, replacing a high-fat meal with a high-carbohydrate one (Nicklas et al. 1993). Indeed, there is a significant positive correlation between energy supplied at breakfast by macronutrients and the same variables in the whole diet in children (Navia et al. 1997).

Although many studies have addressed and sometimes demonstrated the influence of breakfast or various preloads (Jeff et al. 1989) on energy intake (Festin et al. 1992) and food choices during the subsequent eating occasions in experimental conditions, it appears that, in free-living conditions, the influence of such a high-energy breakfast on nutrient supplies throughout the day is modest. The total daily fat and protein intakes are not different in the three situations in spite of obvious energy compensation after the low-energy breakfast.

The existence of a satiating effect of high-carbohydrate meals, as compared with high-fat ones, has been established (Rolls et al. 1988; Cotton et al. 1994; Raben et al. 1996): the subjects on the high-energy breakfast reported a lower hunger rating only in the morning $2 \mathrm{~h}$ after breakfast. As a consequence, morning snacks were less frequent and significantly lower in energy after the high-energy breakfast or the free breakfast than after the low-energy breakfast.

Significantly higher fasting values for triacylglycerol are reported after adaptation to high-carbohydrate diets (Truswell, 1994). However, in the current study, the total diet, even after the high-carbohydrate breakfast, contains only $48 \%$ energy from carbohydrates, which cannot be considered as a truly high-carbohydrate diet. It is not possible to determine, in this present study, if this minor change in carbohydrate intake alone, or the whole increase in energy intake or both are involved in these metabolic changes. Nevertheless it appeared to be sufficient to induce changes in serum triacylglycerol concentrations and consequently in HDL-cholesterol concentrations, although the values always remained within the normal range. Although such changes cannot be assumed to increase risk for cardiovascular events, they are in the direction generally recognised as unfavourable for long-term health maintenance. After a change to a high-carbohydrate diet, the increase in triacylglycerol concentration is transitory with a return to normal values after several weeks (Truswell, 1994). However, it is not known whether the increase in triacylglycerol is also transitory when additional carbohydrate is provided by a single meal in the day. Moreover, the influence of long-term high-carbohydrate diets on postprandial lipaemia is not known in normal subjects and has yet to be more precisely investigated (Frayn \& Kingman 1995).

In our study, after the high-energy breakfast the morning peaks of blood glucose and insulin were associated with a low level of free fatty acids. Though the glycaemic response after the two types of breakfast was very different, there was no second-meal effect for the glycaemic response after lunch. This contradicts the work which showed secondmeal effects after the breakfast when the previous evening's dinner contained foods with a different glycaemic index (Wolever et al. 1988). In contrast, there was a second-meal effect for lipid oxidation in our study. The inhibition of lipid oxidation by carbohydrate load is now well documented, so that excess carbohydrate intake tends to promote temporary storage of fat (Jebb et al. 1996; Stubbs et al. 1997) under conditions of energy balance. The results of the present study confirm these observations and indicate also that the carbohydrate load of the breakfast inhibits lipid oxidation after lunch, though this lunch had the same fat content in the two periods and insulin or glucose patterns were not different between the two groups. Lipid balance was more positive after the standardised lunch at the end of the high energy breakfast period than after the low-energy breakfast period.

In our study no change in body weight was observed during the two periods. However, taking into account the positive lipid balance after the lunch in the highcarbohydrate breakfast period, the absence of decrease in total daily lipid intake and the strong inhibition of lipid oxidation throughout the day, it may be assumed that body weight could increase with time if long-term adaptation does not occur. Although there is currently no association of high-carbohydrate diet with obesity (Hill \& Prentice, 1995), the unfavourable long-term effects of the high-energy breakfast as performed in the present study cannot be excluded. Longer studies on a larger scale are thus required before drawing definitive conclusions.

In conclusion, the results reported in this study do not support the current recommendation to increase energy consumption at breakfast up to $25 \%$ of total daily energy, at least for a continental-type breakfast in free-living conditions. However, the study did not address the problem of micronutrient insufficiency for which the value of $25 \%$ of total daily energy intake at breakfast could be valid. Thus longer studies with a larger sample size are still required.

\section{Acknowledgements}

This work was supported by the Department of Nutrition of Nestlé-France, Marne la Vallée. We thank Dr Heikki Koistinen for English editorial assistance.

\section{References}

Benton D \& Parker YY (1998) Breakfast, blood glucose, and cognition. American Journal of Clinical Nutrition 67, 772S-778S.

Cotton JR, Burley VJ, Westrate JA \& Blundell JE (1994) Dietary fat and appetite: similarities and differences in the satiating effect of meals supplemented with either fat or carbohydrate. Journal of Human Nutrition and Dietetics 7, 11-24.

De Castro JM \& Elmore DK (1988) Subjective hunger relationships with meal patterns in the spontaneous feeding behaviour of humans: evidence for a causal connection. Physiology and Behavior 33, 561-569.

Devaney BL, Gordon AR \& Burghardt JA (1995) Dietary intakes of students. American Journal of Clinical Nutrition 61, 205S-212S.

Favier JC, Ireland-Ripert J \& Feinberg M (1995) Répertoire Général des Aliments. Table de Composition. (General List of Foods. Table of Composition) Paris: TecDoc Lavoisier Publ.

Ferrannini E (1988) The theoretical basis of indirect calorimetry: a review. Metabolism 37, 287-301.

Friedewald W, Levy, R \& Frederikson D (1972) Estimation of the concentration of LDL-cholesterol in plasma without use of preparative ultracentrifuge. Clinical Chemistry 18, 499-502. 
Festin RW, Rolls BJ, Moran TH, Kelly TH, McNelis AL \& Fischman MW (1992) Caloric, but not macronutrient, compensation by humans for required-eating occasions with meals and snack varying in fat and carbohydrate. American Journal of Clinical Nutrition 55, 331-342.

Frayn KN \& Kingman SM (1995) Dietary sugars and lipid metabolism in humans. American Journal of Clinical Nutrition 62, 250S-263S.

Hercberg S, Preziosi P, Galan P, Yacoub, N \& Deheeger M (1996) La consommation du petit déjeuner dans l'étude du Val de Marne: la valeur nutritionnelle du petit déjeuner et ses relations avec l'équilibre global et le statut minéral et vitaminique (Breakfast consumption in the Val de Marne study: nutritional value of breakfast and its relationship to global diet balance and vitamin and mineral status). Cahiers de Nutrition et Diététique 31, S18-S25.

Hill JO \& Prentice AM (1995) Sugar and body weight regulation. American Journal of Clinical Nutrition 62, 264S-273S.

Jebb SA, Prentice AM, Goldberg GR, Murgatroyd PR, Black AE \& Coward WA (1996) Changes in macronutrient balance during over- and underfeeding assessed by 12-d continuous wholebody calorimetry. American Journal of Clinical Nutrition 64, 259-266.

Jeff KL, Young SN \& Blundell JE (1989) The effect of protein or carbohydrate breakfasts on subsequent plasma amino acid level, satiety and nutrient selection in normal males. Pharmacology, Biochemistry and Behavior 34, 829-837.

Le Moullec N, Deheeger M, Preziosi P, Monteiro P, Valeix P, Rolland-Cachera MF, Potier de Courcy G, Christides JP, Cherouvrier F, Galan, P \& Hercberg S (1996) Validation des documents photographiques utilisés pour évaluer la quantité d'aliments ingérés par les sujets de l'étude Suvimax (Validation of photographic documents used to estimate the amounts of foods eaten by subjects in the Suvimax study). Cahiers de Nutrition et Diététique 31, 158-164.

Morgan KJ, Zabik ME \& Stampley GL (1986a) The role of breakfast in diet adequacy of the US adult population. Journal of the American College of Nutrition 5, 551-563.

Morgan KJ, Zabik ME \& Stampley GL (1986b) Breakfast consumption patterns of US children and adolescents. Nutrition Research 6, 635-646.

Navia B, Requejo AM, Ortega RM, Sobaler AML, Quintas ME, Andres P, Redondo MR \& Rivas T (1997) The relationship between breakfast and whole diet energy profiles in a group of preschool children. Annals of Nutrition and Metabolism 41, 299-306.

Nicklas TA, Bao W, Webber LS \& Berenson GS (1993) Breakfast consumption affects adequacy of total daily intake in children. Journal of the American Dietetic Association 93, 886-891.

Raben A, Holst JJ, Christensen NJ \& Astrup A (1996) Determinants of post-prandial appetite sensations: macronutrient intake and glucose metabolism. International Journal of Obesity 20 , 161-169.

Resnicow K (1991) The relationship between breakfast habits and plasma cholesterol levels in schoolchildren. Journal of School Health 61, 81-85.

Rolls BJ, Hetherington, M \& Burley VJ (1988) The specificity of satiety: the influence of food of different macronutrient content on the development of satiety. Physiology and Behavior 43, $145-153$.

Ruxton CHS \& Kirk TR (1997) Breakfast: a review of associations with measures of dietary intake, physiology and biochemistry. British Journal of Nutrition 78, 199-213.

Stanton JL \& Keast DR (1989) Serum cholesterol, fat intake and breakfast consumption in the United States population. Journal of the American College of Nutrition 8, 567-572.

Stubbs RJ, Prentice AM \& James WP (1997) Carbohydrates and energy balance. Annals of the New York Academy of Science 23, 44-69.

Truswell AS (1994) Food carbohydrates and plasma lipids - an update. American Journal of Clinical Nutrition 59, 710S-718S.

Wolever TMS, Jenkins DA, Ocana AM, Rao VA \& Collier GR (1988) Second-meal effect: low-glycemic index foods eaten at dinner improve subsequent breakfast glycemic response. American Journal of Clinical Nutrition 48, 1041-1047.

Wrinkler G, Doring A \& Keil U (1999) Meal patterns in middleaged men in southern Germany: results from the Monica Augsburg dietary survey 1984/85. Appetite 32, 33-37. 